\title{
Front Matter: Volume 10840
}

, "Front Matter: Volume 10840," Proc. SPIE 10840, 9th International Symposium on Advanced Optical Manufacturing and Testing Technologies: Micro- and Nano-Optics, Catenary Optics, and Subwavelength Electromagnetics, 1084001 (24 January 2019); doi: 10.1117/12.2524913 and Testing Technologies (AOMATT2018), 2018, Chengdu, China 


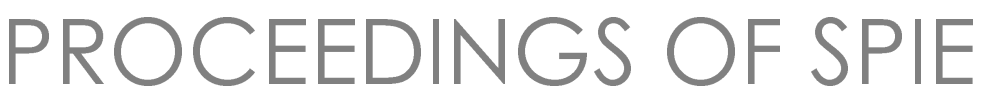

\title{
9th International Symposium on Advanced Optical Manufacturing and Testing Technologies
}

\section{Micro- and Nano-Optics, Catenary Optics, and Subwavelength Electromagnetics}

\author{
Mingbo Pu \\ Xiong Li \\ Bin Fan \\ Min Gu \\ Reinhart Poprawe \\ Xiangang Luo \\ Editors
}

\section{6-29 June 2018 \\ Chengdu, China}

Organized by

Institute of Optics and Electronics, Chinese Academy of Sciences (China)

Sponsored by

COS-The Chinese Optical Society (China)

IOE-Institute of Optics and Electronics, Chinese Academy of Sciences (China)

Published by

SPIE 
The papers in this volume were part of the technical conference cited on the cover and title page. Papers were selected and subject to review by the editors and conference program committee. Some conference presentations may not be available for publication. Additional papers and presentation recordings may be available online in the SPIE Digital Library at SPIEDigitalLibrary.org.

The papers reflect the work and thoughts of the authors and are published herein as submitted. The publisher is not responsible for the validity of the information or for any outcomes resulting from reliance thereon.

Please use the following format to cite material from these proceedings:

Author(s), "Title of Paper," in 9th International Symposium on Advanced Optical Manufacuring and Testing Techologies: Micro- and Nano-Optics, Catenary Optics, and Subwavelength Electromagnetics, edited by Mingbo Pu, Xiong Li, Bin Fan, Min Gu, Reinhart Poprawe, Xiangang LUo, Proceedings of SPIE Vol. 10840 (SPIE, Bellingham, WA, 2019) Seven-digit Article CID Number.

ISSN: 0277-786X

ISSN: 1996-756X (electronic)

ISBN: 9781510623224

ISBN: 9781510623231 (electronic)

Published by

SPIE

P.O. Box 10, Bellingham, Washington 98227-0010 USA

Telephone +1 3606763290 (Pacific Time) · Fax +1 3606471445

SPIE.org

Copyright $@$ 2019 , Society of Photo-Optical Instrumentation Engineers.

Copying of material in this book for internal or personal use, or for the internal or personal use of specific clients, beyond the fair use provisions granted by the U.S. Copyright Law is authorized by SPIE subject to payment of copying fees. The Transactional Reporting Service base fee for this volume is $\$ 18.00$ per article (or portion thereof), which should be paid directly to the Copyright Clearance Center (CCC), 222 Rosewood Drive, Danvers, MA 01923. Payment may also be made electronically through CCC Online at copyright.com. Other copying for republication, resale, advertising or promotion, or any form of systematic or multiple reproduction of any material in this book is prohibited except with permission in writing from the publisher. The CCC fee code is $0277-786 \mathrm{X} / 19 / \$ 18.00$.

Printed in the United States of America.

Publication of record for individual papers is online in the SPIE Digital Library.

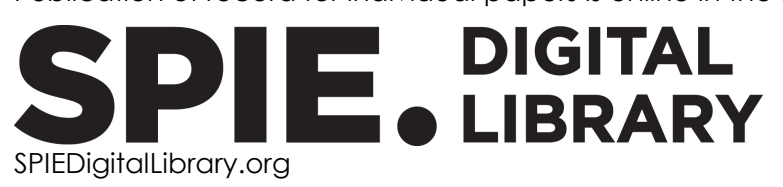

Paper Numbering: Proceedings of SPIE follow an e-First publication model. A unique citation identifier (CID) number is assigned to each article at the time of publication. Utilization of CIDs allows articles to be fully citable as soon as they are published online, and connects the same identifier to all online and print versions of the publication. SPIE uses a seven-digit CID article numbering system structured as follows:

- The first five digits correspond to the SPIE volume number.

- The last two digits indicate publication order within the volume using a Base 36 numbering system employing both numerals and letters. These two-number sets start with $00,01,02,03,04$, 05, 06, 07, 08, 09, OA, OB ... 0Z, followed by 10-1Z, 20-2Z, etc. The CID Number appears on each page of the manuscript. 


\title{
Contents
}

\author{
vii Authors \\ ix Symposium Committees \\ Xi AOMATT 2018 Sponsors
}

MICRO- AND NANO-OPTICS, CATENARY OPTICS, AND SUBWAVELENGTH ELECTROMAGNETICS

1084002 Fano resonance based on a subwavelength semi-annular-rectangular cavity resonator [10840-1]

$1084003 \quad$ Non-paraxial diffraction of tiny pinhole illuminated by partially coherent light [10840-2]

1084004 Design for dynamic wavefront manipulation based on phase change materials [10840-3]

1084005 An all-dielectric metasurface with asymmetric wavefronts for oppositely propagating circularly polarized light [10840-5]

1084006 Composite Ag-Ni metal mesh based transparent conductive film for electromagnetic interference shielding application [10840-6]

1084007 Sensing characteristics of the gold-silver alloy waveguided metallic photonic crystals [10840-7]

1084008 Optical responsivity of mechanical resonators based on suspended membranes of graphene and transition metal dichalcogenides [10840-8]

1084009 Realization of Moiré imaging by flat micro lens array [10840-9]

10840 OA Practical superoscillation element design for far field non-scanning superresolution imaging [10840-10]

10840 OB Trade-offs between stress control and blister avoidance in MEMS devices [10840-14]

10840 OC Tunable multi-modes resonator based on MIM plasmonic waveguides with circular cavity and rectangular baffle [10840-15]

10840 OD High sensitivity plasmonic sensor using hybrid structure of graphene stripe combined with gold gap-ring [10840-17] 
10840 OE Dual-band coherent perfect absorption based on graphene patterned metasurface with tunable absorption frequency and absorptivity [10840-19]

10840 OG Thermal blooming effect of pulse vortex laser beam propagating through the atmosphere [10840-21]

$10840 \mathrm{OH} \quad$ Theoretical study of strained black phosphorus photodetector integrated with silicon waveguide [10840-22]

$10840 \mathrm{Ol} \quad$ A wide-angle and polarization-insensitive tunable metamaterial absorber based on graphene [10840-24]

10840 OJ Study on wavelength division multiplexing with chirped volume Bragg gratings [10840-25]

10840 OK SP resonance angle and Q-factor of metals in ultraviolet band [10840-27]

10840 OM Extraordinary optical transmission of the double square ring metal nanocomposite structures [10840-29]

10840 0N Performance improvement in inverted organic solar cells by incorporating core-shell SiO $@$ @Au plasmonic structures [10840-32]

$1084000 \quad$ Manipulation on thermal radiation spectrum and its polarization with laser manufactured periodic surface patterns [10840-33]

10840 OP The spectroscopic and molecular constants studies of the ground and first excited states of $\mathrm{O}_{2}$ molecule by CCSD(T) and MRCI methods [10840-36]

$108400 Q \quad$ A new long-range single nanotube hybrid plasmonic waveguide [10840-37]

10840 OR A terahertz metamaterial analog of electromagnetically induced transparency and its application in loss detection [10840-39]

10840 OS Slow light in a slot photonic crystal waveguide with asymmetric dielectric rods [10840-40]

10840 OT Enhance the absorption of organic-inorganic perovskite film by nano-surface engineering [10840-41]

10840 OU Study of the linewidth measurement with scanning electron microscope based on laser interference principle [10840-54]

10840 OV Design of a miniature grating displacement sensor with large range [10840-58]

10840 OW Downstream light intensification induced by Gaussian mitigation pits using micro-milling on rear KDP surface [10840-61]

10840 OX Design and fabrication of a new tungsten-diamond transmission target for micro-computed tomography [10840-66]

10840 OY Fresnel zone plate method for measuring lens transmission wavefront power spectral density [10840-89] 
$108400 Z$ Measurement of optical intercept of micro lens arrays [10840-93]

1084010 The research of single point diamond turning Fresnel lens technology [10840-201]

1084011 Analysis error of machining radial Fresnel lens on roller mold [10840-203]

1084012 Dynamic fractal digital lithography for the fabrication of microlens array [10840-204]

1084013 Fabrication of micro-pyramid structured optical element based on SPDT [10840-205]

1084014 Simulation and experimental study on the precision glass molding for microstructures on optical glass based on relaxation effect [10840-214]

1084015 Research and design of functional microstructures with directional transport for bionic microfluidics [10840-226]

1084016 Research and development of light field microscope for measuring 3D microstructures [10840-229]

1084017 Optimization design and performance test of optical antenna for laser communication [10840-242]

1084018 Athermal design of refractive/diffractive hybrid infrared optical system with large relative aperture [10840-244]

1084019 Design and fabrication of CGH for $820 \mathrm{~mm}$ diameter tertiary mirror surface figure testing without center hole [10840-249]

108401 A Design of wide-spectrum directed multispectral imaging system with visible light [10840-254]

10840 1B Research on two test methods of polarizer extinction ratio [10840-361]

$108401 \mathrm{C}$ Nano-grating structure optimal design of bio-inspired polarized light compass [10840-703]

10840 1D Study on long period fiber grating sensor based on deep-grooved process [10840-733]

10840 IE A multilayer structure with high Vis-absorption based on ultrathin NiCr film [10840-747]

$10840 \mathrm{lF} \quad$ A multi-band terahertz metamaterial absorber with novel structure [10840-787]

10840 IG Research on micro displacement measurement technology based on chromatic confocal method [10840-904] 
Proc. of SPIE Vol. 10840 1084001-6

Downloaded From: https://www.spiedigitallibrary.org/conference-proceedings-of-spie on 26 Apr 2023 Terms of Use: https://www.spiedigitallibrary.org/terms-of-use 


\title{
Authors
}

Numbers in the index correspond to the last two digits of the seven-digit citation identifier (CID) article numbering system used in Proceedings of SPIE. The first five digits reflect the volume number. Base 36 numbering is employed for the last two digits and indicates the order of articles within the volume. Numbers start with $00,01,02,03,04,05,06,07,08,09,0 A, 0 B \ldots . .0 Z$, followed by 10-1Z, 20-2Z, etc.

\author{
Cai, Ming, $O Q$ \\ Cai, Xiaoyong, oU \\ Cai, Xuemei, 1D \\ Cai, Yu, $1 \mathrm{C}$ \\ Cao, Guoyang, 08 \\ Cao, Pengfei, OC \\ Cao, Yang, 1D \\ Chai, Liqun, OY \\ Chang, Shanshan, 1B \\ Chen, Daixie, OU \\ Chen, FengNan, 08 \\ Chen, Guoging, 17 \\ Chen, Li, 02 \\ Chen, Menglei, OK \\ Chen, Mingjun, OW \\ Chen, Shiyu, 06, 09 \\ Chen, Weidong, OE, Ol \\ Cheng, Jian, OW \\ Cheng, Lin, OC \\ Cheng, Wang, 1B \\ Chu, Mingzhang, OU \\ Cui, Yanxia, ON \\ Dang, Shuzhen, OS \\ Ding, Jiaoteng, 19 \\ Ding, Zhulin, $1 \mathrm{E}$ \\ Du, Zhiyuan, OD \\ Duan, Jing, 1A \\ Duan, Lanxi, OK \\ Fan, Bin, 10 \\ Fan, Xuewu, 19 \\ Fang, Cizhe, $\mathrm{OH}$ \\ Fang, Yihong, 02 \\ Feng, Liangjie, 19 \\ Gao, Bo, OY \\ Ge, Shaobo, 13 \\ Gong, Hanhan, OM \\ Gu, Deen, 1E \\ Guo, Changwei, OJ \\ Guo, Yawen, 11 \\ Han, Genquan, $\mathrm{OH}$ \\ Han, Jia, 07 \\ $\mathrm{Hao}, \mathrm{Yue}, \mathrm{OH}$ \\ Hao, Yuying, ON \\ $\mathrm{He}, \mathrm{Miao}, \mathrm{O} 2$ \\ $\mathrm{He}$, Xiaodong, $\mathrm{OC}$ \\ $\mathrm{He}$, Xiaofeng, $1 \mathrm{C}$ \\ $\mathrm{He}$, Yuhang, OY \\ $\mathrm{Hu}, \mathrm{Bin}, \mathrm{OD}$ \\ $\mathrm{Hu}$, Bingbing, $\mathrm{OM}$
}

\author{
Hu, Zeyu, $O Q$ \\ Huang, ShiMing, OG \\ Huang, Cuiying, 07 \\ Huang, Sha, OE, Ol \\ Huang, Wangxia, OK \\ Huang, Yuetian, 10, 13 \\ Ji, Ting, ON \\ Jiang, Chao, OU \\ Jiang, Chengguo, OP \\ Jiang, Kai, 1A \\ Jiang, Nan, 1B \\ Jiang, Yadong, 1E, 1F \\ Jiang, Yanru, OA, 18 \\ Jin, K. X., OT \\ Jin, Tao, OK \\ Kong, Lingbao, 15, 16 \\ Lei, Jinqiao, $\mathrm{OE}$ \\ Li, Bing, 03, $1 \mathrm{G}$ \\ Li, Han, OU, OX \\ Li, Hang, 07 \\ Li, Hong, 13 \\ $\mathrm{Li}$, Ling, $\mathrm{OE}, \mathrm{Ol}$ \\ Li, Qiang, OY \\ Li, Shijie, 10 \\ Li, Shijie, 13 \\ Li, Xiaofeng, 08 \\ Li, Xiaogin, 13 \\ $\mathrm{Li}, \mathrm{Xu}, \mathrm{OC}$ \\ Li, Xue, OU \\ Li, Yaru, OK \\ Li, Yuee, OC \\ $\mathrm{Li}$, Zimin, OK \\ Liao, Lifen, 1B \\ Liu, Hongmei, 07 \\ Liu, Hongxia, $\mathrm{OQ}$ \\ Liu, Juan, OD \\ Liu, Junbiao, OU, OX \\ Liu, Kai, $1 \mathrm{~A}$ \\ Liu, Ke, OE \\ Liu, Qi, OW \\ Liv, Song, 00 \\ Liu, Yan, $\mathrm{OH}$ \\ Liv, Yanhua, 06 \\ Liv, Yu, 1D \\ Liu, Zhichao, oW \\ Liu, Zhihuai, 12 \\ Lu, Heng, 08 \\ Lu, Yongle, 1D \\ Lu, Zengxiong, 03, 0V, $1 \mathrm{G}$
}


Luo, Ningning, 12

LV, Jian, $1 \mathrm{~F}$

Ma, ChangWei, OR

$\mathrm{Ma}$, Jing, OV, $1 \mathrm{G}$

Ma, Wenying, OR

Ma, Xiaolong, 17

Ma, Yunfeng, 1B

Ma, Yutian, OX

Ma, Zhen, 19

Mao, Wenjing, 08

Meng, Wei Wei, $1 \mathrm{~F}$

Moser, Joel, 08

Mu, Yunyun, 07

Nie, JianYe, OG

Niu, Geng, OX

Osmond, Johann, 08

Pang, Zhihai, 19

Qi, Wei, 03, 1G

Qi, Yuejing, 03, 0V, 1G

Qi, Yunping, OM

Qin, Saisai, OK

Qu, Enshi, OA, 18

QU, Sheng, OQ

Que, Long Cheng, $1 \mathrm{~F}$

Ren, L. X., OT

Ren, Liyong, OA, 18

Reserbat-Plantey, Antoine, 08

Schädler, Kevin G., 08

Shan, Qiu-sha, 1A

Shang, Mingyang, $\mathrm{OZ}$

Shao, Qunfeng, 0C

Shen, Su, 06, 09

Shi, Jianping, OK

Shi, Linlin, ON

Shu, Jing, OS

Su, Jiani, 03, $1 G$

Sun, Quansheng, OB

Tan, Yi, OR

Tang, Li, 13

Tang, Yuzhu, OR

Tian, Chunmin, 1B

Tian, Guobing, $\mathrm{OZ}$

Tong, Peiqian, ON

Wan, Yongjian, 10

Wang, Chinhua, 08

Wang, Fengling, $\mathrm{OE}, \mathrm{Ol}$

Wang, Gaofeng, OB

Wang, Jian, OW

Wang, Junhua, 16

Wang, Junli, OB

Wang, M., OT

Wang, Meng, 07

Wang, Shulong, $O Q$

Wang, Sujuan, 11

Wang, Xibin, 14

Wei, Xiaohong, OY

Wen, Kunhua, 02

Wu, Feng, 06, 09

Wu, Lixiang, $O B$

Wu, Zhenjie, $O Q$
Xie, Jiaqing, 14

Xie, Qingkun, 0A, 18

Xie, Zhengwei, $\mathrm{OE}, \mathrm{Ol}$

Xing, Chunlei, $\mathrm{OZ}$

Xiong, Baoxing, OJ

$\mathrm{XU}$, Feng, $\mathrm{OJ}, \mathrm{OZ}$

$X u$, Guanglu, OU

$X U$, Kaiyuan, $\mathrm{OY}$

$\mathrm{Xu}, \mathrm{Min}, 15,16$

$X \cup, Q i a o$, OW

$X u$, Qinfeng, OJ

$\mathrm{XU}$, Zhenzhen, 15

Yan, JiaWei, OG

Yan, Peipei, 1A

Yan, Ying, 08

Yang, Chen, 08

Yang, Guanghua, 03, $1 \mathrm{G}$

Yang, Hao, OW

Yang, Jianfeng, 17

Yao, Shao, $\mathrm{OH}$

Yao, Yujia, $\mathrm{OZ}$

Yin, Bohua, OU

Yin, Ziqiang, 11

Yong, Kangle, OG

Yong, Zhang, OP

Yu, Han, OP

Yu, Honglin, 04, 05

YU, Jiang, 09

Yu, Qian, 14

Zhai, Tianrui, 07

Zhang, Fei, 04, 05

Zhang, Guiju, OJ

Zhang, Jincheng, $\mathrm{OH}$

Zhang, Lilian, 1C

Zhang, Ming, 04, 05

Zhang, Qingyang, 03, $1 G$

Zhang, Rongzhu, OG

Zhang, Siqing, $\mathrm{OH}$

Zhang, Xinping, 07

Zhang, Zhimin, 12

Zhang, Zhouqi, OC

Zhang, Zichen, $0 \mathrm{O}$

Zhao, Chengjie, ON

Zhao, Dongge, 17

Zhao, Peng, 1B

Zhao, Weixia, OX

Zheng, Chong, 00

Zheng, Weiwei, 09

Zhou, Jia, 14

Zhou, Jinyun, 02

Zhou, Liang, 1A

Zhou, Min, 1D

Zhou, Panyu, 16

Zhou, Tianfeng, 14

Zhou, Xin, 1E

Zhou, Yun, IF

Zhu, Furong, ON

Zhu, Zhanchen, 14

Zou, Kuaisheng, OJ 


\section{Symposium Committees}

Symposium General Chairs

Bingkun Zhou, Tsinghua University (China)

Guangcan Guo, University of Science and Technology of China (China)

Liwei Zhou, Beijing Institute of Technology (China)

Qihuang Gong, Peking University (China)

Henri Lezec, National Institute of Standards and Technology (United States)

Minghui Hong, National University of Singapore (Singapore)

Yuwen Qin, National Natural Science Foundation of China (China)

Yudong Zhang, Chengdu Branch of Chinese Academy of Sciences (China)

Enhai Liu, Institute of Optics and Electronics (China)

International Advisory Committee

Wenhan Jiang, Institute of Optics and Electronics (China)

Yuen-Ron Shen, University of California, Berkeley (United States)

Myung K. Cho, National Optical Astronomy Observatory (United States)

Organizing Committee

Jinghua Cao, CAS Bureau of International Cooperation (China)

Yadong Jiang, University of Electronic Science and Technology of China (China)

Li Yang, Institute of Optics and Electronics (China)

Program Committee

Hu Yang, Institute of Optics and Electronics (China)

Xiaodi Tan, Beijing Institute of Technology (China)

Ting Xu, Nanjing University (China)

Qiao Xu, China Academy of Engineering Physics (China)

Xuanming Duan, Chongqing Institute of Green and Intelligent

Technology (China)

Xue Feng, Tsinghua University (China)

Junsheng Yu, University of Electronic Science and Technology of China (China)

Xinbin Cheng, Tongji University (China) 
Zheyu Fang, Peking University (China)

Rui Zhou, Xiamen University (China)

Changtao Wang, Institute of Optics and Electronics (China)

\section{Conference Chairs}

Xiangang Luo, Institute of Optics and Electronics (China)

Min Gu, RMIT University (Australia)

Xiaodi Tan, Beijing Institute of Technology (China)

Ting $\mathbf{X} \mathbf{u}$, Nanjing University (China)

Zheyu Fang, Peking University (China)

Xinbin Cheng, Tongji University (China)

Zinan Wang, University of Electronic Science and Technology of China (China)

Mingbo Pu, Institute of Optics and Electronics (China)

Xiong Li, Institute of Optics and Electronics (China) 


\title{
AOMATT 2018 SPONSORS
}

\author{
Organized by \\ Institute of Optics and Electronics, Chinese Academy of Sciences (China) \\ Sponsored by \\ COS-The Chinese Optical Society (China) \\ IOE-Institute of Optics and Electronics, Chinese Academy of Sciences \\ (China) \\ Technical Co-sponsor \\ SPIE \\ Supported by \\ Ministry of Science and Technology of China (China) \\ Chinese Academy of Sciences (China) \\ National Natural Science Foundation of China (China)
}


Proc. of SPIE Vol. 10840 1084001-12 Downloaded From: https://www.spiedigitallibrary.org/conference-proceedings-of-spie on 26 Apr 2023
Terms of Use: https://www.spiedigitallibrary.org/terms-of-use 